\title{
O ENCONTRO DIALÓGICO ENTRE A JUSTIÇA E AS POPULAÇÕES RIBEIRINHAS
}

\section{${ }^{1}$ Simone Maria Palheta Pires ${ }^{2}$ Helena Cristina Guimaraes Queiroz Simoes}

\begin{abstract}
RESUMO
A pesquisa visa, sob a perspectiva do modelo de itinerância fluvial desenvolvido pelo Tribunal de Justiça do Estado do Amapá, refletir sobre a relação dialógica entre os ribeirinhos e o Judiciário amapaense, averiguando se as diferenças entre a linguagem jurídica e a ribeirinha causa obstáculos para a garantia do acesso à justiça. Especificamente, busca compreender a importância da interlocução entre ribeirinhos e operadores do direito para a democratização dos serviços judiciários. Por fim, identificar o que é necessário para uma boa prestação jurisdicional em itinerâncias. O estudo tem uma abordagem qualitativa baseada em pesquisa bibliográfica e em pesquisa documental.
\end{abstract}

Palavras-chave: Acesso à Justiça, Justiça Itinerante, Ribeirinhos, Linguagem

\section{EL REUNIÓN DIALOGIC ENTRE LA JUSTICIA Y LAS POBLACIONES DE RIBERA}

\section{RESUMEN}

La investigación tiene como objetivo, desde la perspectiva del modelo de itinerancia río desarrollado por el Estado de Amapá Tribunal de Justicia, reflexionar sobre la relación dialógica entre el poder judicial de ribera y Amapá, comprobar las diferencias entre el lenguaje jurídico y la causa de ribera obstáculos para garantizar el acceso la justicia . Específicamente busca entender la importancia del diálogo entre los profesionales de la costa y de abogados para democratizar el poder judicial. Por último, identifica lo que es necesario para su adjudicación adecuada de itinerancias . El estudio tiene un enfoque cualitativo basado en búsqueda.

Palabras-claves: Acceso a la Justicia, Justicia Itinerante, Bordeando, Lenguaje

\footnotetext{
1 Doutoranda pela Universidade Federal de Minas Gerais - UFMG, Minas Gerais (Brasil). Professora pela Universidade Federal do Amapá - UNIFAP, Amapá (Brasil). E-mail: eliasimone@hotmail.com
}

2 Doutora pela Universidade Federal de Uberlândia - UFU, Minas Gerais (Brasil). Professora pela Universidade Federal do Amapá - UNIFAP, Amapá (Brasil). E-mail: hcsimoes@unifap.br 


\section{INTRODUÇÃo}

O direito de acesso à justiça passou a estar no primeiro ponto de pauta da justiça brasileira desde a mudança do paradigma constitucional. Após a entrada em vigor da Constituição Federal de 1988 (CF/88), a efetividade do acesso à justiça é medida que precisa ser implementada de forma ampla. Nesse caminhar, as estruturas do Poder Judiciário brasileiro precisam ser revistas para que a atual roupagem antagônica que impede a efetividade de uma jurisdição justa seja transformada em uma estrutura mais democrática e menos encastelada.

Cappelletti e Garth (1988) lembram que o antigo conceito liberal e individualista de acesso à justiça precisou ceder lugar a uma justiça de massas em razão da explosão de litigiosidade promovida pela democratização e valorização dos direitos humanos. Esse processo de mudança gerou avanços, mas possivelmente gerou muito mais questionamentos sobre a necessidade de se descobrir rotas alternativas e menos tortuosas para a democratização da justiça.

A justiça itinerante surgiu, nesse contexto, com o objetivo de alcançar uma demanda reprimida que vive à margem da sociedade, uma demanda periférica que possui poucas ou nenhuma possibilidade de invocar à jurisdição diante de um conflito de interesses. E tornou-se realidade no Brasil, tendo o Estado do Amapá como um dos Estados precursores desta estratégia de efetivar o direito fundamental de acesso à justiça.

Este estudo buscou evidenciar a importância da interlocução entre o Poder Judiciário amapaense e os ribeirinhos, especificamente aqueles que habitam no arquipélago do Bailique, em razão da justiça itinerante fluvial, uma vez que o Tribunal de Justiça do Estado do Amapá (TJAP) desbravou a floresta amazônica brasileira, saindo de sua sede localizada na capital do Estado do Amapá, Macapá, para alcançar uma comunidade ribeirinha tradicional que possui características culturais, sociais e tradições que são bem distintas do "povo da cidade". Uma comunidade que possui ainda uma linguagem própria que precisa ser compreendida para que haja uma verdadeira interação, uma relação dialógica.

Os argumentos do texto estão articulados em três momentos: a) descrição da comunidade do Bailique com o escopo de retratar o modo de vida dos ribeirinhos e as características sociais, econômicas e políticas em que vivem; b) relato da prática da justiça itinerante fluvial no Amapá com base em pesquisa documental, buscando 
revelar a entrega da prestação jurisdicional e o relacionamento do TJAP com a comunidade local; c) discussão sobre a importância da interlocução entre a justiça e o jurisdicionado na prática da justiça itinerante fluvial, em razão de suas especificidades e da necessidade de efetividade e democratização da prestação jurisdicional.

\section{O BAILIQUE}

O Bailique ou o arquipélago do Bailique, no Estado do Amapá, é definido pelo Instituto Brasileiro de Geografia e Estatística (IBGE) como um distrito do município de Macapá. É composto pelas Ilhas de Bailique, Brigue, Curuá, Faustino, Franco, Marinheiro, Igarapé do Meio e Parazinho. Está localizado na Foz do Rio Amazonas e limita-se ao Norte com o rio Araguari e ao Sul com o Canal do Norte, a leste limita-se com o Oceano Atlântico e a Oeste com a região do Pacuí (VIEIRA e ARAÚJO NETO, 2006).

Com base no Censo Demográfico 2010 do IBGE, a população do Arquipélago do Bailique representa $2 \%$ da população do município de Macapá, totalizando 7.618 habitantes. Almeida et al (2013) ressaltam que a população que vive nos núcleos urbanos das ilhas é pequena, aproximadamente 1.500 pessoas. A maior parte $(80,55 \%)$ vive no meio rural (IBGE, 2013).

Em 2010 foram recenseados 1.481 domicílios, sendo 20,53\% localizados nos núcleos urbanos das ilhas e 79,47\% nas áreas rurais. Em média residem cinco pessoas por domicílio. Mas existem famílias mais numerosas. As famílias possuem acesso à energia elétrica de formas variadas, sendo que 41,5\% utilizam a rede de distribuição da Companhia de Eletricidade do Amapá (CEA) e 56,4\% utilizam outras fontes que, modo geral, envolve o uso individual e/ou comunitário de motores a diesel para geração de energia, principalmente, durante a noite. Mas, ainda existe um percentual de 5\% dos domicílios que não possuem acesso à energia (ALMEIDA et al, 2013).

Aproximadamente um terço dos domicílios não possui banheiro e em $66,4 \%$ existe apenas um que é utilizado coletivamente. A água de consumo doméstico em $68 \%$ dos domicílios é obtida diretamente dos cursos naturais como rios, lagos e igarapés, sendo que no meio rural este percentual é de 83\%. Quanto à destinação do lixo, $72,38 \%$ queimam ou enterram nos quintais do próprio domicílio e 23,5\% contam com o suporte de serviço de coleta. Existem ainda 3,38\% que jogam o lixo em cursos naturais de água, contribuindo para a degradação ambiental (ALMEIDA et al, 2013). 
Nestas comunidades há uma forte participação de programas governamentais de transferência de renda. Os principais benefícios recebidos são bolsa família e o Seguro Defeso. Também existem muitas famílias com pessoas que recebem aposentadoria e pensões do Ministério da Previdência Social (MPS).

As famílias que habitam o arquipélago do Bailique desenvolvem diversas atividades produtivas entre as quais se destacam a pesca artesanal, agricultura de subsistência, o extrativismo vegetal e, mais recentemente, a apicultura (VIEIRA; ARAÚJO NETO, 2006). Também é comum a prestação de serviços em carpintaria, construção civil e outros serviços gerais. A combinação destas atividades é uma estratégia de polivalência importante para o sustento e sobrevivência destas famílias que vivem num contexto de pobreza rural (ALMEIDA et al, 2013).

Nos últimos vintes anos o arquipélago do Bailique exibiu crescimento no número de organizações e movimentos sociais. Essas entidades têm finalidades diversas tais como: a representação dos interesses dos trabalhadores; busca de alternativas de geração de renda; valorização das mulheres em várias esferas da vida social; práticas religiosas e as que se empenham na melhoria das condições de vida das comunidades (ALMEIDA et al, 2013).

O Bailique é formado por florestas de várzea, possui um ecossistema típico da região amazônica no qual algumas áreas são periodicamente inundadas pela maré, o que impossibilita o acesso a determinadas comunidades em algumas épocas do ano.

Os habitantes moram em palafitas, as ruas das comunidades são a maioria formadas por pontes de madeira. O nível de escolaridade é muito baixo e o que predomina é o analfabetismo (DESTRI, 2007). Esse quadro foi reduzido com a implantação de escolas de ensino fundamental pela Prefeitura Municipal de Macapá.

Ferraz (2007) ao desenvolver pesquisa de campo no arquipélago asseverou que em 2005 a comunidade era muito carente, pois não havia nas comunidades do Bailique nenhuma infraestrutura como: saneamento básico, água encanada, energia elétrica, postos de saúde e policiamento. As casas, chamadas de palafitas, não possuíam móveis nem eletrodomésticos e abrigavam no mínimo oito pessoas, entre adultos e crianças. Inclusive, naquele ano não havia transporte regular para capital, caso fosse necessário, normalmente em razão de algum problema de saúde, o transporte utilizado eram as "voadeiras".

\footnotetext{
${ }^{1}$ Barco (canoas) pequeno com motor.
} 
As comunidades do Bailique são típicas comunidades ribeirinhas que vivem em função do rio. O rio é a fonte de alimentos, é a via de transporte, é o local de lazer para as famílias, é a vida dos ribeirinhos. É muito comum ver os "curumins"” usando canoas para irem às escolas da região. Comum também é o preparo do peixe a "beira" do rio pelas mães de família.

O nome "ribeirinho" está relacionado com o espaço geográfico onde habitam, ou seja, ribeirinha é a pessoa que mora às margens de rios, lagos ou igarapés. $\mathrm{Na}$ realidade o ribeirinho é aquele que tem um relacionamento mais profundo com o rio, não basta morar às margens do rio, mas o rio passa a ser um elemento constitutivo de sua vida e de seu modo de ser (REZENDE, 2010). Para Gonçalves (2012, p 33) "o ribeirinho é o representante da Amazônia, à medida que desenvolveu todo o seu saber na convivência não somente com outros sujeitos, mas com os rios e matas". Portanto, o ribeirinho não pode ser dissociado do seu habitat.

Em 1996 foi implantada a justiça itinerante no Amapá e a justiça itinerante fluvial operacionalizada através de jornadas periódicas para o arquipélago do Bailique com o barco denominado "Tribuna: A justiça vem a bordo", , doado pela Fundação Banco do Brasil.

Pini (2002) recorda que o Poder Judiciário amapaense foi um dos pioneiros na implantação da justiça itinerante no Brasil, em razão disso, os juizados no Amapá foram instalados em todas as comarcas desde a edição da Lei n. 9.099/95. Foram criados juizados descentralizados nos bairros e segundo ela:

Há um posto avançado instalado literalmente no meio da Floresta Amazônica, para atender uma comunidade ribeirinha, uma região bem isolada, que fica distante do continente - é um arquipélago. Muitas pessoas imaginam que a floresta não é habitada, mas lá estão o caboclo e o homem branco. A Floresta Amazônica possui na região que atendemos, hoje, em torno de setenta comunidades. É importante que nos desloquemos para encontrá-los, porque eles não têm condições de chegar a cidade. Em virtude de tais peculiaridades, foram implantados em nosso Estado, na presidência do Desembargador Mario Gurtyev de Queiroz, em 1996, os juizados itinerantes. Costumo dizer que não somos pioneiros nesse modelo de prestação jurisdicional. Talvez o nosso mérito, se houver algum, é o de termos consolidado esse

\footnotetext{
${ }^{2}$ É um palavra muito utilizada pelos povos amazônicos que designa "criança". Tem origem tupiguarani. Fonte: <http://www.dicionarioinformal.com.br/curumin>.

${ }_{3}^{3}$ Barco com dois andares e capacidade para transportar setenta pessoas, equipado com uma sala de audiência completa. As primeiras jornadas duravam em média cinco dias.
} 
tipo de serviço, porque sabemos que é muito fácil iniciar uma atividade nova no serviço público, o difícil é mantê-la e levála adiante (PINI, 2002, p. 71-75).

Sobre a temática acesso à justiça e itinerância, cabe pontuar a pesquisa coordenada pelo Instituto de Pesquisa Econômica Aplicada (IPEA, 2012), a qual demonstrou que existem óbices econômicos, sociais, políticos e geográficos que aumentam a distância entre o jurisdicionado e o Poder Judiciário. Tais óbices inviabilizam o acesso à justiça e, assim, detectá-los se faz necessário para que a análise de mecanismos aptos a suplantá-los conduza a um método eficaz para fundamentar a elaboração de políticas de inclusão e efetivação dos direitos.

No Estado do Amapá, além de todos os óbices apontados pela pesquisa do IPEA (2012), os aspectos geográficos da região geram uma impossibilidade ainda maior aos moradores das regiões ribeirinhas, pois o Estado está encravado na floresta amazônica e as vias de acesso são somente fluviais/marítimas. Ou a Justiça se desloca até a comunidade, ou a comunidade nunca terá uma oportunidade de se deslocar até o prédio do Tribunal, em razão da distância, da ausência de recursos financeiros, da dificuldade no transporte regular e da falta de informação sobre os direitos.

Apesar da aproximação entre o Judiciário e as comunidades ribeirinhas por meio da justiça itinerante fluvial, não há nenhum projeto público ou particular que empodere a população local de seus direitos e que seja realizado de forma continuada. O que normalmente acontece é somente a divulgação via rádio comunitária do período em que ocorrerá a jornada itinerante, dando publicidade aos serviços que serão prestados.

\section{AS JORNADAS ITINERANTES FLUVIAIS}

A justiça itinerante é disciplinada pelo Tribunal de Justiça do Estado do Amapá (TJAP) na Resolução n. 023/2005, aprovada pelo Pleno Administrativo. A Resolução define que as jornadas itinerantes podem ser realizadas pelo primeiro e segundo grau de jurisdição quando este se reúne através do pleno, secção única e câmara única em outra comarca fora da capital.

As jornadas itinerantes podem ser terrestres ou fluviais. As fluviais são realizadas periodicamente e têm competência para conciliar, processar e julgar todas as causas originárias ou recursais da justiça estadual. Os feitos instaurados pela justiça 
itinerante estadual de primeiro grau, julgados ou não, são distribuídos às varas competentes.

As jornadas contam com a parceria de algumas instituições e órgãos públicos que trabalham juntos para distribuir justiça, cidadania e solidariedade. As instituições parceiras são: Ministério Público; Defensoria Pública; Instituto Nacional do Seguro Social (INSS); Polícia Técnico-Científica do Amapá (POLITEC); Polícia Militar; Companhia de Abastecimento de Água e Esgoto do Amapá (CAESA); Companhia de Eletricidade do Amapá (CEA); médicos; dentistas; enfermeiros e contadores de história (Projeto “Mala Mágica).

Ferraz (2007) relatou sua experiência quando acompanhou uma das jornadas da justiça itinerante fluvial amapaense:

O movimento no barco era constante, além da busca pelos serviços de justiça, as pessoas se reuniam em torno da Corte Itinerante em busca de serviços médicos, odontológicos, psicológicos, kit para desinfecção de água e até mesmo para pedir comida e dinheiro. Naquela jornada foram realizados 3.285 atendimentos médicos e odontológicos, correspondentes a quase metade da população do arquipélago, então estimada em 7.000 (sete mil) habitantes (FERRAZ, 2007, p. 4).

O TJAP escolheu Bailique para ser atendido pelo Juizado Itinerante Fluvial por ter detectado uma carência muito grande por justiça e pela distância que impedia os ribeirinhos de irem até a comarca de Macapá. "A iniciativa de ir até eles partiu da própria Justiça. Infelizmente não tinham seus moradores a consciência de que podiam exigir os serviços judiciários, do Executivo ou o olhar da sociedade" (PINI, 2003).

Em 2014 foi realizada a 111a. jornada itinerante e o servidor José Nivaldo Barbosa Vieira, responsável pela organização e infraestrutura da jornada informou que $^{4}$ nas primeiras jornadas os conflitos que chegavam até a justiça itinerante eram basicamente conflitos de terras. Atualmente, aumentou consideravelmente as questões atinentes à prostituição, envolvimento com drogas ilícitas e todo tipo de atos infracionais.

Em relação à contribuição social das inúmeras jornadas itinerante feitas para o arquipélago do Bailique não existem dados estatísticos oficiais documentados. O

\footnotetext{
4 Disponível em: <http://www.diariodoamapa.com.br/cadernos/principal/cidades/item/14931-justicarealiza-a-111-jornal-itinerante-fluvial-no-amapa $>$.
} 
que existe paira na oralidade dos servidores públicos envolvidos com a itinerância, como o relato de Pini (2003), que acompanhou desde o início as jornadas itinerantes como coordenadora do projeto e que atualmente é desembargadora do TJAP:

Mais de dez (10) anos depois e quase 80 jornadas realizadas, não será exagero afirmar que contribuímos para o desenvolvimento social e econômico que a região hoje apresenta. A sistemática presença da justiça e os inúmeros outros serviços públicos do terceiro setor que foram agregando-se ao programa, mudou a realidade de boa parte daquela população (PINI, 2003, p. 1).

De posse desta ambientação sobre o Bailique e as jornadas, é importante tomar o viés da pesquisa, focando na existência ou não de uma preocupação por parte do Judiciário em ouvir os ribeirinhos para otimização da justiça itinerante; focando na existência ou não de um processo dialógico capaz de extrair as verdadeiras necessidades da população mediante uma comunicação pautada na alteridade.

\section{A JURISDIÇÃO COMO AGIR PÚBLICO DEMOCRÁTICO}

No sentido técnico e etimológico, jurisdição é a ação de "dizer o direito". "É função e dever do Estado, é papel-missão do juiz para garantia das partes” (LEAL, 2012, p. 28). Modernamente a ideia da potestividade cedeu lugar a visão de garantia e dever, onde o processo passou a ser um procedimento que é construído em meio a participação ativa das partes envolvidas em igualdade de condições, onde o contraditório deve ser plenamente garantido para a democratização do procedimento.

O processo e a jurisdição são expressões afirmadoras de direitos fundamentais impedindo o arbítrio ou discricionariedade da função estatal. A jurisdição e processo devem espelhar a cidadania processualmente criada pela soberania popular para construção de uma sociedade democrática de direito (LEAL, 2012). Nesse aspecto, o mito de Leviatã onde o Estado era visto com autoridade suprema queda-se ao Estado de Direito que atenta para o devido processo legal e constitucional aberto para participação de todos com perfeita paridade.

O tripé Estado, processo e tutela jurisdicional, modernamente é visto sobre a ótica da cidadania. Leal (2012, p. 55) afirma que a "Constituição pressupõe a existência de um processo como garantia da pessoa humana”. Não há mais espaço 
para um procedimento judicial sem a primazia dos princípios constitucionais atinentes ao devido processo legal e que não tenha como escopo promover cidadania. "A cidadania deve ser garantida pelo processo porque somente este reúne espaços dialógicos de liberdade e de devida paridade, pois não há mais que se falar em distinções entre processo constitucional e infraconstitucional” (LEAL, 2012, p. 31).

O processo deve ser entendido como procedimento desenvolvido em contraditório, com a participação efetiva dos interessados no provimento final. De acordo com Fazzalari (2006) o processo legislativo, que também é espécie de procedimento como o processo judicial, é construído com a participação popular através de representantes/parlamentares, exigência para que seja considerado democrático. O processo judicial deve também ser um espaço democrático onde as partes tenham liberdade para exercerem o contraditório e participarem da construção do provimento judicial.

O juiz, que representa o Estado, logicamente, não participa do contraditório, mas tem o dever de assegurá-lo e de participar atentamente do processo, pois não é terceiro no processo e sim terceiro em relação aos efeitos do provimento. O juiz não pode ser estranho no iter processual, ele faz parte da realidade vivida entre as partes envolvidas. "A decisão não se qualifica como justa apenas pelo critério da rapidez, e se a justiça não se apresentar no processo não poderá se apresentar, também na sentença" (GONÇALVES, 2012, p. 57).

Para que haja participação efetiva das partes no processo, o juiz tem o dever de informar e garantir que a informação seja assegurada para que a parte, querendo, possa intervir em qualquer momento, desde que atendendo as normas que regem o processo. Ocorre, que as ideias de participação e informação estão conectadas a ideia de conhecimento e reconhecimento, por conseguinte, como participar do que é desconhecido?

\subsection{INFORMAÇÃO, CONHECIMENTO E RECONHECIMENTO DE GRUPOS DE JURISDICIONADOS DISTINTOS}

Não estivessem nas margens do rio Amazonas e de seus afluentes, os 7 mil habitantes do arquipélago de Bailique, distrito de Macapá, capital amapaense, poderiam se chamar Fabiano, Sinhá Vitória, Menino mais novo, Menino mais velho. Assim como as personagens de Graciliano Ramos em 
Vidas Secas, eles não conseguem expressar seus problemas, são incapazes de manifestar, em palavras, o que sentem e sofrem" (DESTRI, 2007, p. 1)

Há pouco mais de quinze anos a comunidade ribeirinha do arquipélago do Bailique teve os primeiros contatos com a justiça institucionalizada, com as primeiras jornadas itinerantes que desbravaram a floresta amazônica para alcançar essa área geográfica inóspita.

É correto afirmar que a maioria da população das comunidades do arquipélago do Bailique nunca tiveram nenhum tipo de contato direto com a justiça institucionalizada, antes do encontro com a justiça itinerante. Parte da população nem sequer possuía registro civil, ou seja, não eram cidadãos. A partir das primeiras jornadas a comunidade passou a compreender a importância de usufruir e exigir direitos pelo contato com aqueles que compunham a equipe das jornadas itinerantes.

Por outro lado, o Poder Judiciário amapaense também estava pisando em terreno desconhecido. Não houve nenhuma ação que promovesse um conhecimento prévio da realidade local, não havia pesquisa, dados estatísticos, documentos ou qualquer outra informação oficial que produzisse informações relevantes sobre as comunidades do Bailique. O Poder Judiciário acostumado a lidar com os conflitos da "cidade grande", com um jurisdicionado que vive em cidades, foi ao encontro de um povo desconhecido, com demandas presumidas mais não profundamente conhecidas, um mundo diferente.

A participação de instituições públicas e privadas nas jornadas itinerantes foi pensada, inicialmente, como um atrativo para aproximar a Justiça da população ribeirinha, pois o pouco tempo de divulgação das jornadas não socializou e esclareceu a contento os serviços judiciários. Os dados levantados por Ramos (2009) demonstraram que a procura pelo serviços judiciários eram bem menores comparados a procura dos serviços agregados. "Isso leva à conclusão de que a maior demanda da população do Bailique não é por jurisdição, mas sim por serviços assistenciais do Estado, como os de saúde, saneamento, expedição de documentos etc" (RAMOS, 2009, n.p). Mas, os dados levantados pelo autor não podem pressupor que as demandas não existiam. Tal constatação conduziria um estudo mais aprofundado se a pouca procura pela jurisdição não se devia ao desconhecimento e ao distanciamento entre a população e o judiciário. 
O depoimento de coordenadora das primeiras jornadas, Dra. Sueli Pini, aponta que no início "parecia que estávamos entrando num túnel do tempo, rumo à Idade Média” (O JUDICIÁRIO, 2007). Em sua oralidade sugere o quanto a realidade da comunidade era distinta daquela vivida na cidade e desconhecida para os juízes:

Nós percebemos que milhares de pessoas viviam em estado de exclusão absoluta. Não existia energia, água potável, serviço de saúde, ninguém tinha documentação civil ou recebia algum benefício, tal o estado de isolamento em que estavam $(\mathrm{O}$ JUDICIÁRIO, 2007, p. 7).

É inegável que a política judiciária, como categoria específica de política pública, foi e é de profunda valia para o desenvolvimento das comunidades do Bailique, o acesso à justiça em sentido amplo, ou seja, o acesso à uma ordem jurídica justa está sendo implementado processualmente pelas itinerâncias fluviais. Entretanto, a falta de interlocução com a comunidade impede o reconhecimento sobre sua condição e sobre possíveis soluções de mudança.

Apesar da iniciativa louvável de sair ao encontro do jurisdicionado, havia e há a necessidade de sair de dentro do barco da Justiça para conhecer a realidade do povo. A entrega da jurisdição deve obedecer as regras da realidade circundante para que seja efetiva. Somente a interlocução entre Justiça e ribeirinhos é capaz de proporcionar uma experiência profunda para que o agir, a linguagem e a abordagem do Judiciário sejam mais adequados.

Na visão moderna de jurisdição e processo já tratada ao norte, percebe-se que é imprescindível que o juiz conheça a realidade, a vida e cultura do jurisdicionado para oportunizar uma participação democrática no processo. Sem esta interação, não haverá consenso, não haverá espaço de fala e nem de compreensão.

\subsection{A LINGUAGEM COMO INTERAÇÃO SOCIAL}

Para Habermas (2002), em sua teoria da ação comunicativa, a linguagem não é vista como vê o linguista, mas é vista como uma prática social, não é fruto somente de um consenso entre aqueles que falam, mas deve gerar efeitos no mundo externo. Nesse sentido, a linguagem no processo passa a ser vista como uma prática que 
produz efeito no mundo externo, ela é necessária para que o contraditório seja efetivamente assegurado.

Entre tantas diferenças entre fazer jurisdição na cidade e fazer jurisdição em comunidades ribeirinhas, há a dificuldade do consenso na linguagem que cria mais um obstáculo para minimização do abismo que distancia o Judiciário do jurisdicionado do Bailique, o ribeirinho no caso.

Retomando o mito da caverna de Platão os ribeirinhos do Bailique seriam os prisioneiros do fundo da caverna que conseguem ver somente sombras do Direito, mas que precisam ser conduzidos para fora para conseguirem contemplar o que realmente existe no mundo externo.

É imperativo um encontro entre linguagens e uma troca de experiências para que tanto o Judiciário como os ribeirinhos se conectem em seus objetivos. A conexão se desenvolverá, neste caso, por meio de um contato dialógico que necessita, para alcançar seu fim, de uma interlocução clara onde o encontro de realidades se fará naturalmente.

A ação comunicativa poderá, então, ser o fio condutor entre o desconhecimento da realidade vivida pelos ribeirinhos e a ação do Judiciário através da justiça itinerante. Assim, a tensão entre "faticidade" e "validade" é expressa no sistema jurídico que encontra sua legitimidade na prática do discurso democrático, estabilizando-se pela integração social por meio da jurisdição e pela assimetria das formas de linguagens (HABERMAS, 2002).

O acesso à justiça não se efetiva apenas por estar insculpido na Constituição, mas sim pela participação na construção da jurisdição, o que torna o juiz não um mero aplicador da lei, mas o faz um sujeito sociologicamente atuante no processo. Conforme Habermas (2002), a linguagem, nesse processo, é imprescindível para que a democracia se concretize via acolhimento do melhor argumento.

Sem uma interlocução prévia que servirá de conhecimento, no caso dos ribeirinhos, a compreensão da linguagem fica comprometida.

Rezende (2010, p. 118) afirma que "a cultura necessita da linguagem para estabelecer meios de compreensão do mundo que nos cerca”. A linguagem do ribeirinho é recheada de termos herdados de sua formação social e cultural, muitos dos termos integrados a linguagem do ribeirinho tem origem indígena ou estão relacionados com aspectos vivenciados em seu dia-a-dia, como o nome de plantas, 
peixes, rios e localidades. Eis algumas expressões correntes da linguagem do ribeirinho que foram tomadas como exemplo:

\section{Quadro 1: Expressões e significados}

\begin{tabular}{|l|l|}
\hline \multicolumn{1}{|c|}{$\begin{array}{c}\text { Expressões } \\
\text { ribeirinhas }\end{array}$} & \multicolumn{1}{c|}{ Significados } \\
\hline Banho & Local às margens do rio apropriado para nadar \\
\hline Banzero ou marola & $\begin{array}{l}\text { Pequenas ondas formadas no rio pela passagem de um } \\
\text { pequeno barco }\end{array}$ \\
\hline Buchuda & Mulher grávida \\
\hline Carapanã & Pernilongo \\
\hline Curumim & Criança pequena \\
\hline Escangalhado & Quebrado \\
\hline Fazer mau & Desvirginar \\
\hline Pitiú & Cheiro característico do peixe \\
\hline Tutiço & Pescoço \\
\hline Um, dois & Rápido \\
\hline Zoada & Barulho \\
\hline
\end{tabular}

Fonte: elaboração das autoras.

De outra sorte, o uso da linguagem jurídica usada no dia-a-dia do cotidiano jurídico pode dificultar ainda mais a relação entre ribeirinhos e justiça. Sabemos que existem operadores do direito que se preocupam somente em aplicar o direito, sentenciando conforme os ditames legais, sem sensibilidade com os resultados que a decisão promoverá na vida das partes. O que se espera do juiz é que, além de declarar o direito ao caso concreto, tenha um olhar para o pano de fundo social, já que a dimensão multicultural da sociedade é uma realidade.

No encontro entre juiz e ribeirinho há um confronto de culturas e de linguagem. $\mathrm{O}$ operador do direito possui uma linguagem jurídica, o ribeirinho o seu linguajar peculiar. $\mathrm{O}$ operador do direito possui uma visão de mundo e uma realidade distinta daquela vivida pelos ribeirinhos. Como comportam-se tais atores na mesma cena? As linguagens distintas podem distanciar o ribeirinho do Poder Judiciário e comprometer o seu direito de acesso à justiça? Em caso afirmativo, a solução para o impasse estaria em uma prévia interlocução para gerar conhecimento e reconhecimento entre Judiciário e ribeirinhos? Longe de se oferecer respostas definitivas, o que se propõe é um espaço aberto para reflexão sobre a necessidade de democratizar ao máximo a Justiça para que o direito fundamental de acesso à justiça deixe sua esfera formal e passe a ser uma realidade factual. 


\subsection{A VISÃO DA MAGISTRATURA BRASILEIRA SOBRE A IMPORTÂNCIA DA I NTERLOCUÇÃO PARA A DEMOCRATIZAÇÃO DA JURISDIÇÃO}

Acredita-se que maior parte dos magistrados brasileiros são originários da classe média. Esse dado é intuitivamente observável em razão da realidade social do Brasil, pelas escassas oportunidades que as classes menos favorecidas possuem de terem acesso a melhores condições e oportunidades de educação. O acesso às universidades para negros e jovens das classes menos favorecidas é um problema que tem sido causa de ações e normas que visam equacionar o problema, como o atual sistema de cotas em vigor. O problema, no entanto, reverbera com mais intensidade na admissão, por concursos públicos, dos novos magistrados.

Souza (2004), em uma reflexão da sociologia damattiana, entende que o processo moderno de centralização dos poderes estatais com todo o seu arsenal legislativo de normais gerais e abstratas e do uso da violência, a influência no aparelho psíquico individual para a formação de uma economia emocional específica, tornou-se mais intensa. Isso significa que a psique individual seria o resultado histórico promovido pelo Estado moderno e seu aparato de regulação social.

Fundamentado na teoria do reconhecimento Charles Taylor e na sociologia de Pierre Bourdier, Souza (2004) desenvolve sua ideia de que o pensamento tayloriano e a sociologia de Bourdier se completam no momento em que Taylor apresenta uma nova hierarquia que é eficaz como base da classificação social e do valor diferencial de indivíduos e classes sociais. Souza (2004), então, completa esse pensamento com a ideia de Bourdier sobre o reconhecimento produzido e implementado institucionalmente como núcleo de possibilidade do estabelecimento de distinções sociais a partir de signos sociais percebidos por todos de maneira préreflexiva. Souza informa que:

Para ambos os autores, a singularidade da sociedade moderna se dá precisamente pela produção por uma configuração formada de ilusões do sentido imediato e cotidiano que Taylor denomina de "naturalismo", e Bourdier de "doxa". Tais ilusões produzem um desconhecimento específico dos atores a cerca de suas próprias condições de vida (SOUZA, 2001, p. 84). 
Partindo desse entendimento e da complementariedade entre Taylor e Bourdier, pode-se afirmar que atitudes e práticas são resultado de um conjunto de ideias produzidas e que são introjetadas inconscientemente pelos indivíduos como um "condicionamento pré-reflexivo, automático, emotivo e espontâneo, em outras palavras "inscrito no corpo" de nossas ações, disposições e escolhas" (SOUZA, 2001, p. 85).

Nesse sentido, o magistrado também tem "inscrito em seu corpo" esse conjunto de ideias que de forma pré-reflexiva influencia suas ações. O distanciamento entre grupos sociais é determinado por uma hierarquia de valores que impede a conexão no encontro. É notório que todo e qualquer encontro só se torna positivo quando há conexão e intenção e no caso da relação entre ribeirinhos e Judiciário a intenção fica comprometida pelos elementos pré-reflexivos e a conexão pelo choque da linguagem.

Essa ideia interessante do habitatus funcionando como fios invisíveis que ligam as pessoas por solidariedade e identificação e as separa por preconceito, o que equivale a noção de coordenação de ações sociais consideradas inconscientes e cifradas, impede a riqueza da noção de articulação [...] (SOUZA, 2001, p. 86).

A ideologia da magistratura brasileira impede uma atitude proativa no sentido de buscar uma solução para o distanciamento entre o Judiciário e as classes menos favorecidas socialmente. A ideia de inércia do Judiciário está tão impregnada na mentalidade dos juízes que os impede de perceber que a eliminação do abismo que os afasta da realidade social não compromete a noção de que o Judiciário só poderá exercer a jurisdição quando for provocado. Entretanto, para que a jurisdição seja exercida de forma justa, é imprescindível um conhecimento da realidade vivida pelo jurisdicionado, esse conhecimento não significa, de nenhum modo, a iniciativa para propositura de ações ou coisas similares, significa a eliminação da equidistância para a democratização do sistema judicial.

\section{CONSIDERAÇÕES FINAIS}

As jornadas itinerantes fluviais promovidas pelo Tribunal de Justiça do Estado do Amapá (TJAP) realmente causaram um impacto relevante na realidade 
social das comunidades do Bailique, o que foi comprovado nos dados secundários levantados nesta pesquisa. Ocorre que apesar da iniciativa razoavelmente exitosa do Tribunal não houve uma ação prévia de aproximação dos magistrados com o cotidiano dos ribeirinhos.

As jornadas itinerantes fluviais ocorreram e continuam ocorrendo sem uma otimização dos serviços, da tutela jurisdicional, com base em dados sociológicos da realidade local.

O impacto multicultural entre a justiça da cidade e a esperada pela comunidade ribeirinha, respeitando seu modo típico de ser, acabou e acaba por gerar um distanciamento irreconciliável, promovendo a ideia do que deveria ser exatamente combatido, a de que o Poder Judiciário é inatingível e encastelado.

A inércia da jurisdição não pode impedir a acessibilidade, e a acessibilidade deve ser empreendida no sentido de derrubar as muralhas socioculturais que rodeiam o Judiciário.

O encontro da justiça institucionalizada com povos tradicionais deve ser visto como um desafio e como uma visão de respeito as minorias, esse respeito perpassa pela humildade em reconhecer as identidades locais para que os óbices culturais sejam eliminados.

Sem dúvida, a busca por essa nova forma de jurisdição obriga o operador do direito a reformular o conceito de cidadania combinando-o com o de prestação jurisdicional. Assim, antes de os magistrados se preocuparem com a aplicação pura da norma, devem fazer uma ponderação prévia sobre a origem dos conflitos.

O multifacetado contexto social obriga os operadores do direito a saírem de sua zona de conforto e a mergulharem na realidade circundante, como também em adquirirem novos saberes como, por exemplo, a linguagem dos grupos sociais que fazem parte do âmbito de sua jurisdição.

A reflexão sobre uma suposta ideologia da magistratura brasileira, que impede o encontro principalmente com grupos periféricos socialmente, deve ser uma constante porque se trata de um conjunto de ideias assimiladas de forma préreflexivas (no sentido de Bourdier).

A comunicação entre o ribeirinho e os operadores do direito suscita o conhecimento da linguagem própria do ribeirinho. Já que o magistrado nas jornadas itinerantes se despe de suas vestes talares, deve também se despir de uma linguagem jurídica que inviabilize o diálogo com os ribeirinhos. Quanto a interação através da 
linguagem:

[...] para efetividade da comunicação, a mensagem deve ser efetuada num código linguístico comum aos falantes. O emissor deve preocupar-se com a linguagem utilizada, posto que o receptor deve compartilhar desta para decodificá-la. Dentro de uma perspectiva macro, ambos os falantes compartilham de um mesmo código, a língua portuguesa falada no Brasil, mas se formos considerar a linguagem que estão inseridos, comunidades que possuem seu próprio socioleto, teremos dois códigos [...] (REZENDE, 2010, p. 93).

Diante destes dois códigos, a linguagem jurídica e a linguagem do ribeirinho, deve haver uma interação e uma convivência para que a comunicação seja eficaz e para que seja alcançado o desiderato que é a plena efetividade do acesso à justiça, sem exclusões.

Preparar os ribeirinhos para dialogar com o Judiciário é uma necessidade. Praticar ações de socialização que levem o conhecimento sobre direitos humanos, cidadania e acesso à justiça é um caminho para interação, conhecimento e reconhecimento. Nesse processo, o que espera é que haja um encontro entre a linguagem dos dois mundos e nesse encontro a comunicação deixará de ser uma barreira para se tornar a solução.

\section{REFERÊNCIAS}

ALMEIDA, Marineide Pereira de; SOARES, Ana Cristina de Paula Maués; LIMA, Josinete Pereira; SANTOS, Marcos Antônio Souza dos. A participação da mulher em organizações sociais rurais na Amazônia: estudo de caso no Arquipélago do Bailique, Estado do Amapá. PRACS: Revista Eletrônica de Humanidades do Curso de Ciências Sociais da UNIFAP. Macapá, n. 6, p. 19-31, dez. 2013. Disponível em: <http://periodicos.unifap.br/index.php/pracs>. Acesso em: 01 nov 2014.

ALMEIDA, Selene Maria de. O Paradigma Processual do Liberalismo e o Acesso à Justiça. Conferência proferida no "Seminário sobre Acesso à Justiça", realizado pelo Centro de Estudos Judiciários, nos dias 24 e 25 de abril de 2003, no auditório do Tribunal de Contas do Estado de Minas Gerais, Belo Horizonte - MG. R. Cej, Brasília, n. 22, p. 20-24, jul/set. 2003. Disponível em: <http://www.jf.jus.br/ojs2/index.php/revcej/article/viewFile/559/739>. Acesso em: 10 nov 2014.

ASKOUL, Marco Antonio. Justiça Itinerante. São Paulo: Editora Juarez, 2006.

CAPPELlETTI, Mauro; GARTH, Bryant. Acesso à Justiça. Trad. Ellen Gracie Nortfleet. Porto Alegre: Sérgio Antônio Fabris, 1988. 
DESTRI, Luíza. A justiça que vai aonde o povo está - vitórias e desafios da Justiça Itinerante Fluvial, que há dez anos percorre rios e igarapés do Amapá. Getúlio, n. 2, ano 1, mar/2007, Fundação Getúlio Vargas, Rio de Janeiro. Disponível em: <http://bibliotecadigital.fgv.br/dspace/bitstream/handle/10438/7217/Ed2_AJusticaQu eVai.pdf?sequence=1>. Acesso em: 10 out 2014.

FAZZALARI, Elio. Instituições de Direito Processual. 8 ed. Trad. Eliane Nassif. São Paulo: Bookseller, 2006.

FERRAZ, Leslie S. Democratização do Acesso à Justiça: A Justiça Itinerante Fluvial do Amapá, no Rio Amazonas. In: Anais do III Encontro Anual da Associação Nacional de Direitos Humanos, Pesquisa e Pós-Graduação (ANDHEP). Set/2007. UFPB, João Pessoa - PB. Disponível em: <http://www.andhep.org.br/anais/arquivos/VIIencontro/gt04-03.pdf>. Acesso em: 10 out 2014.

GONÇALVES, Aroldo Plínio. Técnica processual e teoria do processo. 2. ed. Belo Horizonte: Del Rey, 2012.

HABERMAS, Jürgen. Agir comunicativo e razão destrancendentalizada. Rio de Janeiro: Tempo Brasileiro, 2002.

LEAL, Rosemiro Pereira. Teoria geral do processo: primeiros estudos. 11. ed. Rio de Janeiro: Forense, 2012.

INSTITUTO BRASILEIRO DE GEOGRAFIA E ESTATÍSTICA (IBGE). Censo Demográfico 2010. Disponível em: <http://www.ibge.gov.br>. Acesso em: 18 set. 2013.

INSTITUTO DE PESQUISA ECONÔMICA APLICADA (IPEA). Plataforma IPEA de Pesquisa em Rede. Democratização do acesso à Justiça e efetivação de direitos: A Justiça Itinerante no Brasil. Diretoria de Estudos e Políticas de Estado, Instituições e Democracia (DIEST/IPEA). $2012 . \quad$ Disponível em: <http://www.ipea.gov.br/redeipea/images/pdfs/termo_referencia/Termo_de_Referenci a_Democratizacao_do_Acesso_a_Justica.pdf >. Acesso em: 08 out 2014.

NALINI, José Renato. A Rebelião da Toga. São Paulo: Millennium, 2006.

O JUDICIÁRIO. Justiça nas "ilhas que dançam" - As aventuras do Juizado Itinerante do Amapá levam cidadania às margens do Amazonas. Ano I, n. 9, jun/2007. São Paulo: Tribunal de Justiça de São Paulo, 2007.

PINI, Sueli Pereira. Relatório da $50^{a}$ jornada itinerante fluvial. Macapá: Juizado Especial Cível de Macapá, 2003.

A Experiência do Juizado Itinerante do Amapá. Conferência proferida no $2^{\circ}$ Congresso Brasileiro de Administração da Justiça. R. CEJ, Brasília, n. 17, p. 71-75. Abril/jun. 2002. Disponível em: <http://daleth.cjf.jus.br/revista/numero17/painel43.pdf>. Acesso em: 01 out 2014.

PIRES, Luís Manuel Fonseca. Um diálogo sobre a justiça: a justiça arquetípica e a justiça deôntica. Belo Horizonte: Fórum, 2012. 
RAMOS, Carlos Fernando S. Política judiciária como instrumento de inclusão social: A experiência do juizado itinerante fluvial do estado do Amapá. Texto não publicado. Apresentado no Curso de Mestrado em Direito Ambiental e Políticas Públicas da Universidade Federal do Amapá. Macapá: [s.n], 2009, n.p.

REZENDE, Maria Idalina Monteiro. A linguagem jurídica e sua expressão no contexto ribeirinho: a Justiça Itinerante no Baixo Madeira. Dissertação (Mestrado) Universidade Federal de Rondônia - Campos Guajará-Mirim. 2010. Disponível em: <http//www.livros01.livrosgratis.com.br/cp146122.pdf>. Acesso em: 30 set 2014.

SANTOS, Boaventura de Sousa. Pela mão de Alice: o social e o político na pósmodernidade. 14 ed. São Paulo: Cortez, 2013.

Para uma revolução democrática da justiça. 3 ed. São

Paulo: Cortez, 2003.

SENA, Adriana Goulart. Formas de Resolução de Conflitos e Acesso à Justiça. Rev.

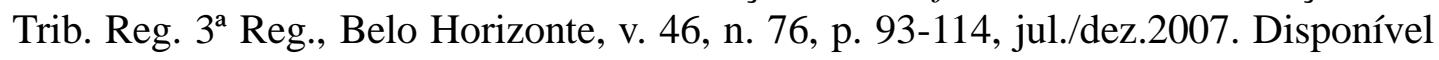
em: <http://www.trt3.jus.br/escola/download/revista/rev_76/Adriana_Sena.pdf $>$. Acesso em: 01 out 2014.

SOUZA, Jessé de. A gramática social da desigualdade brasileira. Revista Brasileira de Ciências Sociais. Vol. 19. n. 54. 2001. Disponível em: <http://www.scielo.br/pdf/rbcsoc/v19n54/a05v1954.pdf>. Acesso em: 30 set 2014.

. A sociologia dual de Roberto Da Matta: Descobrindo nossos mistérios ou sistematizando nossos autoenganos? Revista Brasileira de Ciência Sociais. Vol. 16. n. 45. 2004. Disponível em: <http://www.scielo.br/pdf/rbcsoc/v16n45/4330>. Acesso em: 10 out 2014.

TRIBUNAL DE JUSTIÇA DO ESTADO DO AMAPÁ. Apresentação das necessidades de infraestrutura e manutenção do Poder Judiciário - Análise da demanda social para o Poder Judiciário no Estado do Amapá - Período 1995-2007. Macapá: Tribunal de Justiça do Estado do Amapá, 2007.

A justiça itinerante. Disponível em: <http://www.tjap.gov.br/jus_itinerante.php>. Acesso em: 01 out 2014.

Resolução n. 023/2005-TJAP, de 29 de junho de 2005. Disciplina o funcionamento da Justiça Itinerante Estadual em $1^{\circ}$ e $2^{\circ}$ graus e dá outras providências. Diário Oficial do Estado, n. 3550, 19 mar. 2005.

VIEIRA. I. M.; ARAÚJO NETO. M. D. Aspectos da socioeconomia dos pescadores de camarão da Ilha do Pará (PA) e Arquipélago do Bailique (AP). 